\title{
Infection of the foot with Peptococcus magnus
}

\author{
P. J. SANDERSON 1 \\ From North Middlesex Hospital, Edmonton, N18 1QX
}

SUMmary Peptococcus magnus was the predominant organism in severe infections of the feet in three diabetic patients. In one patient the organism was found also in blood culture, and in two it was repeatedly recovered from the feet, usually in pure culture.

Peptococcus magnus is a biochemically inactive anaerobic Gram-positive coccus similar in morphology to the staphylococcus. It has been found (Smith, 1975) as part of the normal flora of the mouth, vagina, and skin. Previous reports (Pien et al., 1972; Spaulding et al., 1974) have described significant infections with this organism, but knowledge of its pathogenicity is incomplete since speciation of the organism is rarely undertaken in clinical laboratories. This report draws attention to the possible significance of Pc. magnus in infective lesions of the foot.

\section{Material and methods}

SPECIMENS

Samples of pus on swabs were received in the laboratory within a few hours of collection.

\section{MEDIA}

Specimens were cultured aerobically on Columbia agar with $5 \%$ horse blood (Lab M, Salford, Lancs) and on MacConkey agar (Lab M). Anaerobic culture was made on Columbia agar containing $5 \%$ horse blood and on Brucella agar containing $5 \%$ horse blood, $0.5 \mu \mathrm{g} / \mathrm{ml}$ menadione (vitamin $\mathrm{K} 3$ ), and $75 \mu \mathrm{g} / \mathrm{ml}$ kanamycin (Lab M).

\footnotetext{
ANAEROBIC CULTURE TECHNIQUE

Anaerobic culture was carried out in steel jars fitted with an enlarged sachet (Baldwin, 1975) containing 8.5 g 'cold catalyst D' (Engelhard Industries, Cinderford, Glos). The catalyst was renewed each week. The jars were set up as recommended by Watt and Collee (1974) using a gas mixture of $90 \%$ hydrogen and $10 \%$ carbon dioxide.

IDENTIFICATION OF ISOLATES

Aerobic isolates These were identified convention-

1Present address: Department of Microbiology, Northwick Park Hospital and Clinical Research Centre, Harrow, Middlesex HA1 3UJ

Received for publication 28 July 1976
}

ally using methods described by Cowan (1974).

Anaerobic isolates Atmospheric growth requirements were confirmed by subculture of one colony on to two Brucella agar plates (with supplements but without kanamycin). One plate was incubated anaerobically and the other in air with $10 \% \mathrm{CO}_{2}$ to exclude microaerophilic organisms and contaminating aerobes.

Anaerobic isolates were then subcultured into thioglycollate broth supplemented with haemin (British Drug Houses, London), $5 \mu \mathrm{g} / \mathrm{ml}$, menadione (Sigma Ltd, London), $5 \mu \mathrm{g} / \mathrm{ml}$, sodium bicarbonate, $1 \mu \mathrm{g} / \mathrm{ml}$, and Tween 80 (Sigma Ltd) $0.1 \%$ (the latter component was not used for Gram-negative cocci and Gram-negative bacilli). Identification methods were those recommended by Sutter et al. (1975). The media used for biochemical tests and the interpretation of the results were made according to the Anaerobe Laboratory Manual of the Virginia Polytechnic Institute (Holdeman and Moore, 1972).

\section{IDENTIFICATION OF PEPTOCOCCUS MAGNUS}

The following tests were undertaken: (1) fermentation of glucose, lactose, maltose, sucrose, fructose, cellobiose, and melezitose; (2) hydrolysis of aesculin; (3) liquefaction of gelatin; (4) reduction of nitrate; (5) formation of indole; and (6) production of black pigment.

Media Carbohydrates and aesculin (Hopkin and Williams, Romford, Essex) were dissolved in carbohydrate basal medium (Holdeman and Moore, 1972) supplemented with Tween $800.1 \%$ at final concentrations of $1.0 \%$ and $0.5 \%$ respectively. Gelatin discs (Oxoid Ltd, Basingstoke) were added to the same medium. Nitrate broth (BBL Laboratories, Wembley, Middlesex) supplemented with Tween 80 $0.1 \%$ was used for tests of nitrate reduction and indole formation. 
Methods Three millilitres of the culture in thioglycollate broth of the organism under investigation were added to $0.2 \mathrm{ml}$ of a 1:20 dilution of Tween 80 in distilled water. Each of the media described above was used in $5.0 \mathrm{ml}$ volumes in bijou bottles. Five drops of the culture of the organism were added to the carbohydrate and gelatin media and $1.0 \mathrm{ml}$ to the aesculin medium and nitrate broth. Results were read after five days' incubation at $37^{\circ} \mathrm{C}$. Bromocresol was used as $\mathrm{pH}$ indicator. Ferric chloride was used for aesculin hydrolysis. The nitrate broth was split into two equal portions; one was tested for nitrate reduction according to Cowan (1974) and the other was tested for indole after extraction with xylol by the addition of Ehrlich's reagent. Cultures were examined for pigment production after five days' incubation on Brucella agar. The culture in thioglycollate broth was checked for viability and purity by subculture on to Brucella agar plates. One plate was incubated anaerobically and the other in air plus $10 \% \mathrm{CO}_{2}$.

Strains which did not ferment carbohydrates and were negative for aesculin hydrolysis, nitrate reduction, indole formation, and production of black pigment but were able to liquefy gelatin were regarded as belonging to the species $P c$. magnus.

Peptococcus prevotii, which is also biochemically inactive, is distinguished from Pc. magnus by inability to liquefy gelatin. However, rare strains of $P c$. prevotii which are able to hydrolyse gelatin may be separated from Pc. magnus by gas liquid chromatography; this was not done in this study. Peptococcus variabilis was not distinguished from $P c$. magnus, as suggested by Holdeman and Moore (1972).

Antibiotic sensitivity testing A colony of Pc. magnus was spread over the surface of a plate of DST agar (Oxoid Ltd). Discs of benzyl penicillin (2 units), clindamycin $(2 \mu \mathrm{g})$, cepaloridine $(15 \mu \mathrm{g})$, and cotrimoxazole $(25 \mu \mathrm{g})$ were then placed on the agar. Sensitivity or resistance was determined after overnight incubation by comparing diameters of zones of inhibition with those of a known sensitive control organism.

\section{Case reports}

\section{CASE 1}

A 76-year-old diabetic lady on tolbutamide was admitted in a confused mental state with a temperature of $103.0^{\circ} \mathrm{F}\left(39.4^{\circ} \mathrm{C}\right)$ and a pulse of $110 / \mathrm{min}$. The WBC was $8.4 \times 10^{9} / 1$, increasing to $12.4 \times 10^{9} / 1$ three days later. A chest $x$-ray film was normal and a mid-stream urine yielded no bacterial growth. The patient had not received antibiotics. A swab from an ulcer on the gangrenous right hallux cultured a penicillin-resistant Staphylococcus aureus, haemolytic streptococci of group $\mathrm{C}$, and Pc. magnus. A blood culture taken on admission grew only $P c$. magnus. The patient was treated with ampicillin and then also with clindamycin phosphate intravenously for five days after receipt of the blood culture result. She made a rapid recovery.

Each isolate of Pc. magnus from this patient, and from the following two patients, was sensitive to benzyl penicillin, clindamycin, and cephaloridine. The isolates from each patient were resistant to cotrimoxazole.

\section{CASE 2}

A 49-year-old diabetic man on diabenase was admitted with a malodorous infection of the right fifth toe extending into the deep plantar tissues. Swabs from the lesion yielded haemolytic streptococci of group B, Peptostreptococcus anaerobius, Veillonella parvula, and Pc.magnus. $X$-ray films of the right foot showed destructive changes in the fifth phalanx and gas shadows in the soft tissues. The patient was treated with ampicillin initially and then with both clindamycin orally and benzyl penicillin intramuscularly. Subsequent swabs yielded $P c$. magnus on six occasions without other organisms except a single isolate of a coliform. Persistent purulent discharge cleared slowly during three months' antibiotic therapy with clindamycin and benzyl penicillin.

\section{CASE 3}

A 68-year-old diabetic man on diabenase was admitted with cellulitis of the right foot. The fifth toe was gangrenous and a sinus at its base discharged pus, the odour of which necessitated moving the patient to the end of the ward. The WBC was 12.9 $\times 10^{9} / 1$ and a fever up to $101 \cdot 2^{\circ} \mathrm{F}\left(38.4^{\circ} \mathrm{C}\right)$ occurred for three days after admission. A swab from the sinus yielded Pc. magnus and Streptococcus viridans. The patient was treated with lincomycin orally. $P c$. magnus was again isolated two weeks after admission. The patient was then given clindamycin phosphate intramuscularly for five days. No further organisms were recovered from the foot except a single isolate of Serratia marcescens two months after the patient entered hospital. The fifth toe was later amputated and the cellulitis gradually improved.

\section{OTHER ISOLATIONS}

Pc. magnus was obtained from infected lesions of the feet of 12 patients during the period 1 December 1974 to 30 November 1975. Eleven of these patients were diabetic, including the three patients reported here. In the remaining cases, mixed cultures were obtained and the role of Pc. magnus in the infection was less 
clear. However, in several patients this organism, together with others, was repeatedly isolated and it may have contributed to the infection.

\section{Discussion}

Case reports of infection with $P c$. magnus are rare. However, in surveys of anaerobic organisms from clinical specimens, Pc. magnus is one of the common species of anaerobic Gram-positive cocci recovered. In a recent survey (Wren et al., 1977) of anaerobic organisms in specimens obtained from this hospital, 84 isolates of Pc. magnus were found in a total of 766 specimens. Of 14 isolates obtained in pure culture, four were from the vagina, two from abdominal abscesses, one from an infected abdominal surgical wound, and the remainder from the cases described. The most common source of the organism was infected lesions of the foot where a heavily mixed culture with other organisms was usually found.

It is of interest therefore to attempt to assess the pathogenic potential of $P c$. magnus. The three cases reported here provide evidence of the invasiveness and persistence of the organism despite initial isolation in the presence of other bacteria. The recovery of Pc. magnus from the blood of the first patient demonstrates systemic spread of the organism from the local lesion in the foot, where it was present together with Staph aureus. The persistence of $P c$. magnus for some weeks in the lesions of the foot of two other patients indicates resistance to elimination by both antibiotics and body defences which were successful in removing other bacteria found in the initial specimens.

Pien et al. (1972) described a case of Pc. magnus bacteraemia after dilatation of the urethra and two cases of osteomyelitis in which this organism was isolated in mixed culture from discharges. One of the latter patients was diabetic and in the other $\boldsymbol{P C}$. magnus was later isolated in pure culture. Prévot (1966) describes the recovery of Diplococcus magnus, which corresponds in his nomenclature to $P c$. magnus, from several purulent sources, including osteomyelitis fistula. Lambe et al. (1975) describe seven significant infections associated with pure isolates of $\boldsymbol{P c}$. magnus, including a case of septicaemia and four postoperative wound infections.

The source of $P$ c. magnus in the cases reported was probably the skin. In a survey of 20 healthy adults carried out in this laboratory, 13 yielded Pc. magnus from the skin between the toes. The poor blood supply and slow tissue healing that occurred in the lesions of these patients, and possibly the concomitant diabetes, would predispose to serious and prolonged infection. However, it is suggested that the pathogenicity of the organism itself enabled it to continue the infection when other organisms failed to do so.

I wish to thank Dr I. D. Ramsay and $\mathrm{Mr} T$. Hennebry for permission to report their patients. I am most grateful to Mr M. W. D. Wren and other members of the laboratory staff who performed the bacteriological investigations.

\section{References}

Baldwin, A. W. F. (1975). An improved catalyst sachet for anaerobic jars. J. med. Lab. Technol., 32, 329-330.

Cowan, S. T. (1974). Cowan and Steel's Manual for the Identification of Medical Bacteria, 2nd edition. Cambridge University Press, London.

Holdeman, L. V. and Moore, W. E. C. (1972). Anaerobe Laboratory Manual. Virginia Polytechnic Institute and State University, Blacksburg, Virginia.

Lambe, D. W., Jr., Vroon, D. H., and Rietz, C. W. (1975). Infections due to aerobic cocci. In Anaerobic Bacteria: Role in Disease, edited by A. Balows, R. M. DeHaan, V. R. Dowell, Jr., and L. B. Guze, pp. 585-599. Thomas, Springfield, Illinois.

Pien, F. D., Thompson, R. L., and Martin, W. J. (1972). Clinical and bacteriologic studies of anaerobic grampositive cocci. Mayo Clin. Proc., 47, 251-257.

Prévot, A. R. (1966). Manual for the Classification and Determination of the Anaerobic Bacteria, translated by V. Fredette. Lea and Febiger, Philadelphia. Kimpton, London.

Smith, L. D. S. (1975). The Pathogenic Anaerobic Bacteria, 2nd edition, p. 99. Thomas, Springfield, Illinois.

Spaulding, E. H., Vargo, V., Michaelson, T. C., Korzeniowski, M., and Swenson, R. M. (1974). Anaerobic bacteria: culture and identification. In Opportunistic Pathogens, edited by J. E. Prier and H. Friedman, pp. 87-104. University Park Press, Baltimore.

Sutter, V. L., Vargo, V. L., and Finegold, S. M. (1975). Wadsworth Anaerobic Bacteriology Manual, 2nd edition. Department of Continuing Education in Health Sciences, University Extension, University of California, Los Angeles.

Watt, B. and Collee, J. G. (1974). Practical approaches to the isolation and identification of clinically important nonsporing anaerobes. In Infection with Non-sporing Anaerobic Bacteria, edited by I. Phillips and M. Sussman pp. 7-19. Churchill Livingstone, London.

Wren, M. W. D., Baldwin, A. W. F., Eldon Christine P., and Sanderson, P. J. (1977). The anaerobic culture of clinical specimens: a 14-month study. Journal of Medical Microbiology, in press. 